\title{
Psoriasiform Dermatitis Related with T-Cell Immunoreceptor with Immunoglobulin and Immunoreceptor Tyrosine-Based Inhibitory Motif Domains Inhibitor in a Patient with Non-Small-Cell Lung Cancer
}

\author{
YoungHwan Choi, Donghwi Jang, Hyun Jeong Byun, Se Jin Oh, Cho Rok Kim¹ , Ji-Hye Park, \\ Jong Hee Lee, Dong-Youn Lee \\ Department of Dermatology, Samsung Medical Center, Sungkyunkwan University School of Medicine, ${ }^{1}$ Kye Dermatology Clinic, Seoul, \\ Korea
}

Dear Editor:

MK-7684, an antagonistic agent targeting T-cell immunoreceptor with immunoglobulin and immunoreceptor tyrosine-based inhibitory motif domains (TIGIT), is on phase 1 trial for the treatment of advanced solid tumors since December 2016. We present a case of psoriasiform dermatitis after treatment with MK-7684. Until date, there exists no reported case in English literature about psoriasiform dermatitis associated with TIGIT inhibitor.

A 63-year-old male with non-small-cell lung cancer (NSCLC) failed to respond to classic chemotherapy and was subsequently treated with pembrolizumab (Fig. 1A). After nine months, he developed erythematous plaques on his arms and legs without changes in his nails (Fig. 1B, C). The skin lesion was mild and controlled by topical steroids. Five months later, due to the progression of NSCLC, pembrolizumab was discontinued and MK-7684 was started subsequently. After one month, he developed eryth-

Received April 30, 2019, Revised June 30, 2019, Accepted for publication July 5, 2019

Corresponding author: Ji-Hye Park, Department of Dermatology, Samsung Medical Center, Sungkyunkwan University School of Medicine, 81 Irwon-ro, Gangnam-gu, Seoul 06351, Korea. Tel: 82-2-3410-6578, Fax: 82-2-3410-3869, E-mail: jh1204.park@samsung.com ORCID: https://orcid.org/0000-0002-6699-5202

This is an Open Access article distributed under the terms of the Creative Commons Attribution Non-Commercial License (http://creativecommons. org/licenses/by-nc/4.0) which permits unrestricted non-commercial use, distribution, and reproduction in any medium, provided the original work is properly cited.

Copyright $($ c The Korean Dermatological Association and The Korean Society for Investigative Dermatology ematous scaly plaques on his whole body (Fig. 1D, E). He also developed trachyonychia on his twenty nails (Fig. 1F). He was a non-smoker and had been taking metformin and atorvastatin for more than two years. He denied a past medical history of psoriasis. After a skin biopsy, the lesion was histologically diagnosed as psoriasiform dermatitis (Fig. 2). He was treated with topical steroids and phototherapy. MK-7684 was stopped after the second injection due to exacerbation of psoriasiform dermatitis. No new lesions had developed after the discontinuation.

Drug-related psoriasis is a side effect of several drugs, such as NSAIDs, antimalarial agents, lithium, beta-blockers and anti-programmed cell death 1 (PD-1) antibodies ${ }^{1}$. These drugs can induce psoriasis or exacerbate preexisting psoriasis ${ }^{1}$. The time interval from drug administration to the appearance of the lesion varies from less than four weeks to three months or more ${ }^{1}$.

TIGIT is a new checkpoint receptor target for cancer immunotherapy and thought to be upregulated on T-cells in multiple cancer models ${ }^{2}$. By blocking TIGIT, the interaction of CD155 and CD112 with the costimulatory receptor CD226 can be enhanced in association with activation of T-cell mediated immune response against cancer cells ${ }^{3}$.

In our case, although mild psoriasiform eruption was induced during treatment with pembrolizumab, skin lesions progressed to biopsy-proven psoriasiform dermatitis during treatment with MK-7684. It has been hypothesized that over-activation of T-helper 1 and 17 cells through anti-PD-1 could contribute towards the development of psoriasis $^{4}$. Although the pathological mechanisms of develop- 


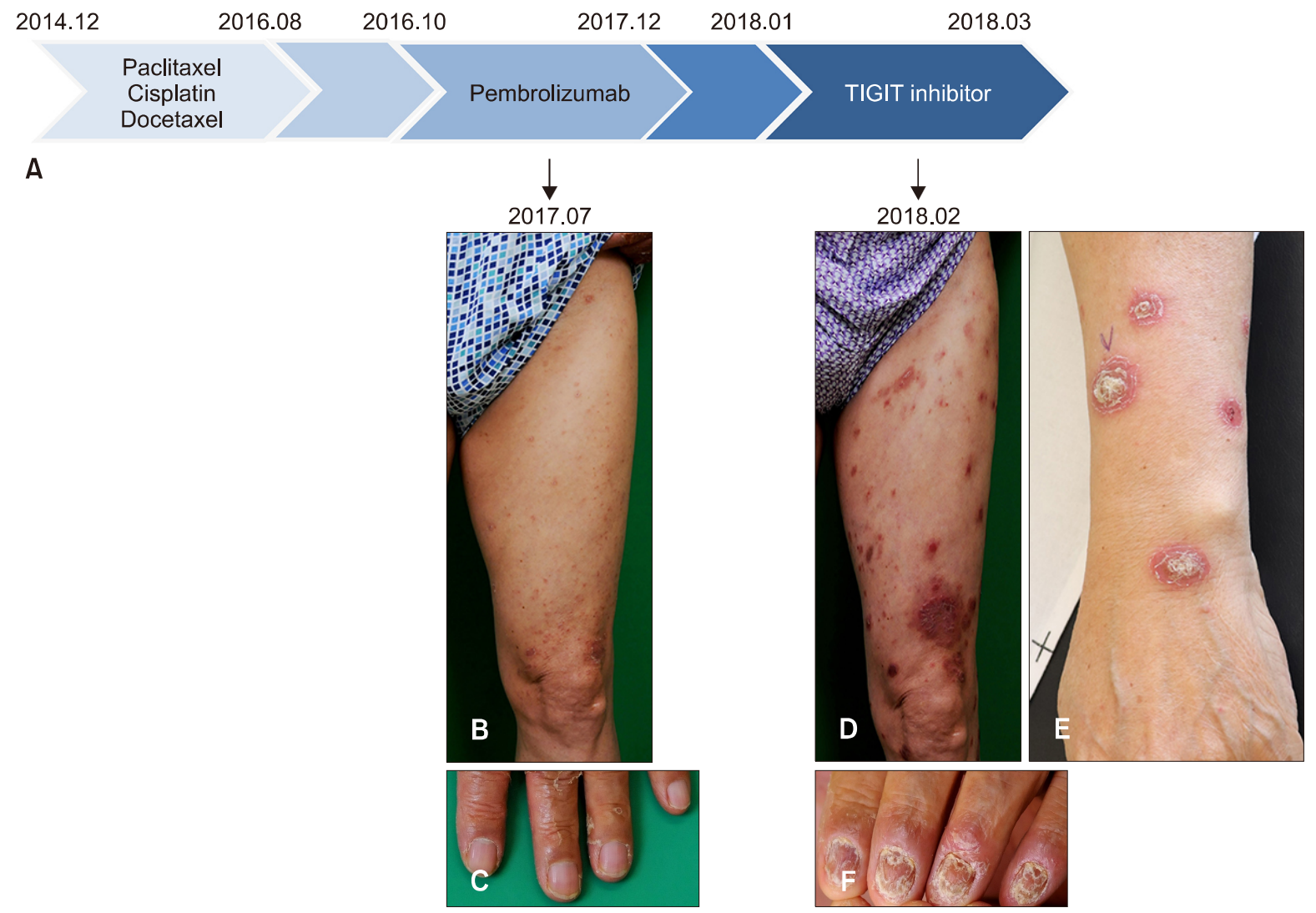

Fig. 1. (A) Timeline of chemotherapy. (B) Erythematous plaques and papules during pembrolizumab treatment. (C) Normal nail plate during pembrolizumab treatment. (D, E) Hyperkeratotic scaly erythematous plaques during T-cell immunoreceptor with immunoglobulin and immunoreceptor tyrosine-based inhibitory motif domains (TIGIT) inhibitor treatment. (F) Nail dystrophy during TIGIT inhibitor treatment. We received the patient's consent form about publishing all photographic materials.
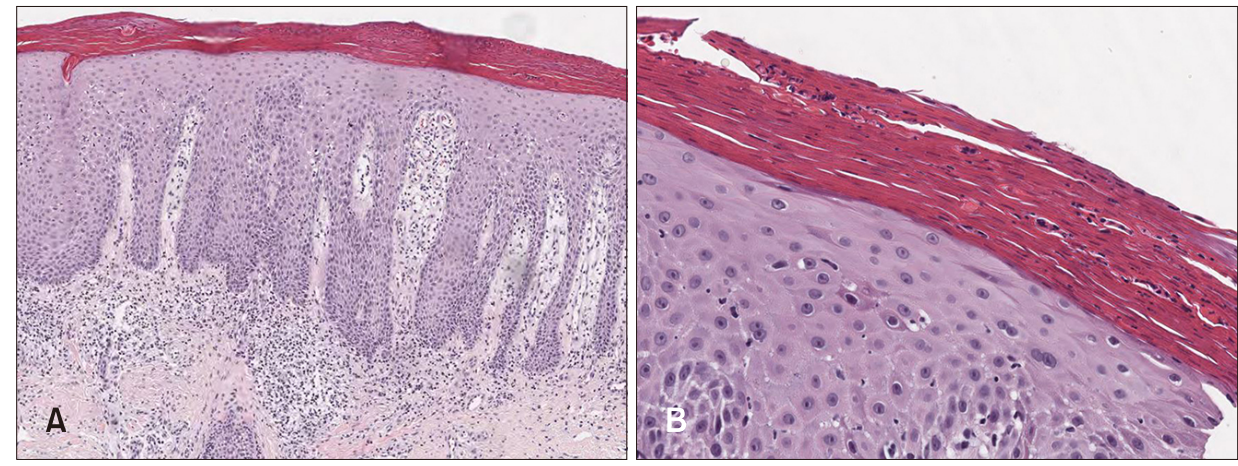

Fig. 2. Histopathological images of skin biopsy specimen of the leg. (A) Acanthosis with elongated rete ridges on epidermis and papillary dermal inflammatory infiltrations $(\mathrm{H} \& \mathrm{E}, \times 100)$. (B) Parakeratosis and microabscess in stratum corneum $(\mathrm{H} \& \mathrm{E}, \times 400)$. ing psoriasiform dermatitis by TIGIT inhibitor are unknown, increased production of cytokines related to psoriasis could be one of the mechanisms ${ }^{5}$. Wang et al. ${ }^{5}$ reported about TIGIT + CD4 + T-cells and cytokine levels in patients with psoriasis. The researchers reported that the activation of TIGIT inhibited psoriatic CD4 + T-cell proliferation, decreased the production of IFN- $\gamma$ and IL-17A, and increased the IL-10 level $^{5}$. They also reported an increase in the production of IFN- $\gamma$ and IL-17A subsequent to treatment with TIGIT inhibitor ${ }^{5}$. We believe that downregulation of TIGIT on CD4+ T-cells might have contributed towards the pathogenesis of psoriasiform dermatitis in our case ${ }^{5}$. Therefore, we claim that clinicians should be aware of the potential development or aggravation of psoriasiform dermatitis when opting for TIGIT inhibitor treatment. 
Brief Report

\section{CONFLICTS OF INTEREST}

The authors have nothing to disclose.

\section{ORCID}

YoungHwan Choi, https://orcid.org/0000-0003-4177-7724

Donghwi Jang, https://orcid.org/0000-0002-3495-4772

Hyun Jeong Byun, https://orcid.org/0000-0002-4354-5655

Se Jin Oh, https://orcid.org/0000-0001-7525-4740

Cho Rok Kim, https://orcid.org/0000-0003-4168-4245

Ji-Hye Park, https://orcid.org/0000-0002-6699-5202

Jong Hee Lee, https://orcid.org/0000-0001-8536-1179

Dong-Youn Lee, https://orcid.org/0000-0003-0765-9812

\section{REFERENCES}

1. Hong J, Bernstein D. A review of drugs that induce or exacerbate psoriasis. J Psoriasis Psoriatic Arthritis 2012;18:2-11.

2. Kurtulus S, Sakuishi K, Zhang H, Joller N, Tan D, Smyth M, et al. Mechanisms of TIGIT-driven immune suppression in cancer. J Immunother Cancer 2014;2(Suppl 3):O13.

3. Dixon KO, Schorer M, Nevin J, Etminan Y, Amoozgar Z, Kondo T, et al. Functional Anti-TIGIT antibodies regulate development of autoimmunity and antitumor immunity. J Immunol 2018;200:3000-3007.

4. Voudouri D, Nikolaou V, Laschos K, Charpidou A, Soupos $\mathrm{N}$, Triantafyllopoulou I, et al. Anti-PD1/PDL1 induced psoriasis. Curr Probl Cancer 2017;41:407-412.

5. Wang FF, Wang Y, Wang L, Wang TS, Bai YP. TIGIT expression levels on CD4 + T cells are correlated with disease severity in patients with psoriasis. Clin Exp Dermatol 2018; 43:675-682.

\title{
Cutaneous Plasmacytosis Showing a Neuronal Involvement in a 35-Year-Old Female
}

\author{
Joong-Heon Suh, Ho-Young Kim, Jae Ho Lee, Soo-Kyung Lee, Un-Ha Lee, Myoung-Shin Kim \\ Department of Dermatology, Sanggye Paik Hospital, Inje University College of Medicine, Seoul, Korea
}

\begin{abstract}
Dear Editor:
Cutaneous plasmacytosis $(\mathrm{CP})$ is a rare skin disorder characterized by multiple reddish-brown patches and nodules that mainly occur on the trunk in adults ${ }^{1}$. Histologically, there is a dermal infiltrate of mature plasma cells. We re-
\end{abstract}

Received January 23, 2019, Revised July 29, 2019, Accepted for publication July 31, 2019

Corresponding author: Myoung-Shin Kim, Department of Dermatology, Sanggye Paik Hospital, Inje University College of Medicine, 1342 Dongilro, Nowon-gu, Seoul 01757, Korea. Tel: 82-2-950-1131, Fax: 82-2931-8720, E-mail: etihwevol@naver.com

ORCID: https://orcid.org/0000-0002-0660-8098

This is an Open Access article distributed under the terms of the Creative Commons Attribution Non-Commercial License (http://creativecommons. org/licenses/by-nc/4.0) which permits unrestricted non-commercial use, distribution, and reproduction in any medium, provided the original work is properly cited.

Copyright $($ c The Korean Dermatological Association and The Korean Society for Investigative Dermatology port a case of 35-year-old female who presented with multiple red to brownish macules and patches on the left side of the trunk with a neuronal distribution (Fig. 1). The lesion appeared 4 years ago without any symptoms of pain or itching. A histopathological examination revealed a dense dermal patch-like cellular infiltration surrounding the follicles and the nerves (Fig. 2). The infiltrate was composed of lymphocytes, histiocytes, and plasma cells. Immunohistochemical staining was positive for CD138, CD3, and CD20. Serum protein electrophoresis and immunoelectrophoresis revealed polyclonal hypergammaglobulinemia. Based on these findings, a diagnosis of CP was made. The patient underwent treatment with systemic corticosteroids and narrowband ultraviolet B for 3 months till date. However, the response to the treatment has been minimal.

In our review of the literature, skin manifestations of $\mathrm{CP}$ were considerably uniform among patients, with multiple reddish to brownish colored scaly patches, nodules, and 